\title{
Harder to Find Than Nemo: The Elusive Image Citation Standard
}

\section{Jennifer Yao Weinraub}

\begin{abstract}
New image citation standards need to be developed for college and graduate students to meet visual literacy standards. The MLA Handbook, 8th edition, and Chicago Manual of Style, 16th edition, do not adequately clarify how to caption, attribute, and cite images. Other image captioning and citing resources are available, but they refer to the $M L A$ and Chicago manuals. Image captions from scholarly journals vary widely and cannot be used as examples for students to follow. Recommendations are also provided for future editions of the MLA Handbook and Chicago Manual of Style.
\end{abstract}

\section{Introduction}

Visual literacy has become an essential component of information literacy. The American Association of School Librarians (AASL) Standards for the 21st-Century Learner, published in 2007, states: "Multiple literacies, including digital, visual, textual, and technological, have now joined information literacy as crucial skills for this century." 1 The ACRL's Visual Literacy Competency Standards for Higher Education, published in 2011, states:

Today's society is highly visual, and visual imagery is no longer supplemental to other forms of information. New digital technologies have made it possible for almost anyone to create and share visual media. Yet the pervasiveness of images and visual media does not necessarily mean that individuals are able to critically view, use, and produce visual content. Individuals must develop these essential skills in order to engage capably in a visually-oriented society. ${ }^{2}$

There are seven ACRL visual literacy standards, and the last one is: "The visually literate student understands many of the ethical, legal, social, and economic issues surrounding the creation and use of images and visual media, and accesses and uses visual materials ethically." ${ }^{3}$ Each standard has two to four "performance indicators," and one of the performance indicators for the seventh standard is: "The visually literate student cites images and visual media in papers, presentations, and projects." Each performance indicator, in turn, has two to seven "learning outcomes," and the learning outcomes for this performance indicator are:

a. Gives attribution to image creators in citations and credit statements to acknowledge authorship and author rights

b. Includes source information in citations and credit statements so visual materials can be reliably found and accessed by other scholars and researchers

c. Cites visual materials using an appropriate documentation style ${ }^{4}$

*Jennifer Yao Weinraub is Librarian at The New School; e-mail: yaoj@newschool.edu. (C2018 Jennifer Yao Weinraub, Attribution-NonCommercial (http://creativecommons.org/licenses/by-nc/4.0/) CC BY-NC. 
According to John Abdul Kargbo, "Modern reference style formats are associated with the information explosion that witnessed a rapid increase in scholarly publications, compelling publishers and writers to find convenient methods to document the different sources they consulted in their publications. ${ }^{5}$ We are now experiencing a new information explosion, this time with digital images. However, current style guides have not evolved in concert with greater image availability, the rise of image use in education, and the development of visual literacy standards. It is problematic for students to "cite visual materials using an appropriate documentation style" because the MLA Handbook, 8th edition and Chicago Manual of Style, 16th edition, inadequately deal with the topic of referencing images. Other resources have been developed to assist students in captioning and citing images, but they all refer back to the style guides. Furthermore, image captions/citations in published scholarly works do not adhere to any conventions and therefore cannot serve as models for students to follow.

\section{Literature Review}

Articles on image captioning and citing are scarce. In an article on the development of ACRL's Visual Literacy Competency Standards for Higher Education, Denise Hattwig, Kaila Bussert, Ann Medaille, and Joanna Burgess write:

Image citation is a foundation issue in academic contexts; images are part of the scholarly conversation that is supported by consistent citation practices. Students need to be aware of what should be included in an image citation, how to format image citations by using accepted documentation styles, and how to adapt citations to a variety of end products (presentations or posters, for example). ${ }^{6}$

Benjamin R. Harris ${ }^{7}$ and Molly J. Schoen ${ }^{8}$ both describe the importance of teaching image citation in visual literacy instruction programs, but they do not describe image citing in detail. Debbie Abilock uses a flowchart to direct students to various sections of the MLA Handbook for citing a "Work of Visual Art," "Photo or Illustration from an Archive," "Photo or Illustration in Hand," or a "Photo or Image (Born Digital). ${ }^{9}$ Gail Lynn Goldberg highlights "common problems and pitfalls students encounter when including graphics in scientific and technical writing, such as missing or inadequate captions, labels, and source information," and she encourages teachers to provide "instruction on when and how to attribute graphic resources such as photographs, drawings, diagrams, charts, and tables." ${ }^{10}$ Although there appears to be congruence on the importance of teaching students how to cite images properly, there is little actual guidance on how to do so.

\section{Methodology}

This study, conducted from 2015 to 2017, evaluates the pertinent sections of the MLA Handbook, 8th edition, and Chicago Manual of Style, 16th edition, plus several other resources, for their usefulness in helping students "cite visual materials using an appropriate documentation style," one of the learning outcomes of the ACRL Visual Literacy Standards. The study focuses on student use of images including photographs, artwork, page views, screenshots, and illustrations (excluding charts, graphs, or diagrams) for coursework in the humanities and social sciences.

In fields such as literature, history, visual arts, performing arts, cultural studies, material culture, gender studies, anthropology, sociology, classical studies, and religion, wider availability of images has led to new opportunities in scholarship. Many images previously available only locally are now available online, and they have been analyzed and described to further enhance their usefulness. These images can reveal 
insights that cannot be found in written texts, and they can be used in innovative scholarly projects. An invitation for submissions to Winterthur Portfolio: A Journal of American Material Culture asks for "more images" and encourages authors to "use a broad range of tools and media" to contribute work such as "a generously illustrated article, a 3-D model, a digital photo essay, or an analytical model."11

The MLA and Chicago guides were chosen because they are both widely used in undergraduate and graduate education. According to the Purdue Online Writing Lab, "MLA (Modern Language Association) style is most commonly used to write papers and cite sources within the liberal arts and humanities,"12 and Chicago style is used in the humanities and social sciences. ${ }^{13}$ The most recent editions as of the year 2016 were assumed to correspond with current image use.

The other guides in this study were chosen for their relevancy as resources for image captioning and citing, their availability to students, and their currency. Each resource was evaluated based on its comprehensiveness, quality and variety of examples, and ease of use for student captioning and citing of images obtained from print and online resources including books, periodicals, databases, and websites, and used in coursework (such as research papers, visual presentations, or online posts).

Five sources of images - one publicly available digital collection, two subscription image databases, and two aggregators - were also examined to identify guidance on image citation. These databases were selected because they are available to academic libraries, they contain various types of images, and they can be used for scholarship in multiple academic disciplines. They were evaluated based on the quality of the image caption or image citation examples. Additionally, a citing tool was evaluated based on the quality of the citation that was produced for this study.

For the study on captions, seventy-six captions were identified in twenty-two journal articles from JSTOR and the journals Dress and Fashion Theory. The database JSTOR was searched using the keyword Vogue in the caption field, and the most relevant results were examined. The database and keyword were chosen based on their potential to provide captions from articles published throughout the twentieth century and early twenty-first century in journals of various academic disciplines. Online versions of Dress and Fashion Theory were also searched to include more recent articles in the study. The number of captions studied was determined to be minimally sufficient for identifying any trends or patterns in published captions.

\section{Analysis and Discussion}

Style guides should provide comprehensive information on image citing. First, they should distinguish between an image caption and image citation. When an image is reproduced in a student research paper, there needs to be a caption or credit statement, not just a citation. The purpose of the caption is to identify or describe the image and to provide credit, while the citation provides source information "so visual materials can be reliably found and accessed by other scholars and researchers." ${ }^{14}$ The caption or credit statement is located in proximity to the image, while the citation may appear as a footnote, endnote, or parenthetical note, and/or in a bibliography, list of illustrations, or list of sources. At times, the title or description and the source are combined together into one reference. The reference would be called a "caption" or "citation" depending on its position on the page. Thus, the terms are sometimes used interchangeably. An image caption can consist simply of a credit statement or credit line, but a caption often also describes the image or relates it to the paper. Because many images do not come with a title, they need to be interpreted and described. A level of subject knowledge may be needed to properly write an image caption or citation. 
It is also helpful for style guides to discuss the purpose of citing images. Image citations serve many of the same purposes as citations of text-based materials. Both help readers locate original sources. Both also provide attribution (for images, attribution should be provided both "in citations and credit statements"15). While citations for text-based materials act as evidence for an argument, citations for images do not. It is an author's choice of a particular image, or her discourse on the image, that supports her argument. Citing text versus images also differ when it comes to the issue of plagiarism. When a student does not cite a quote or an idea, there are usually concerns of plagiarism. However, when a student neglects to cite an image, it is not necessarily a case of plagiarism. If a student reproduces Van Gogh's Sunflowers in a research paper and does not credit it, it is unlikely to be with the intent of, or interpreted as, the student passing the work off as his own. It is unethical, perhaps, but not exactly plagiarized.

\section{Style Guides}

The first style guide in this study, the eighth edition of the MLA Handbook, was published in 2016 and has been substantially revised to be "a guide that [teaches] the principles underlying documentation" rather than "a reference work, which users [consult] at need." 16 Though the MLA guide satisfies the goal of simplifying and streamlining referencing, it does not provide enough guidance on captioning and citing images. The first half of the Handbook, the "Principles of MLA Style," presents a framework intended for citing any type of media, and the second half, "Details of MLA Style," discusses specific topics. In the "Details," there are instructions on how to cite music, films, videos, and television shows, but no instructions on how to cite images.

The other style guide in this study, the 16th edition of the Chicago Manual of Style, was published in 2010 and has sections on "Captions," "Credit Lines," and "Lists of Illustrations," but no section on image citing. ${ }^{17}$ Captions "may consist of a word or two, an incomplete or a complete sentence, several sentences, or a combination." ${ }^{18}$ Complete discretion is given to the writer regarding what the caption should include. The section on credit lines stresses the importance of seeking permission for image use. It states:

A brief statement of the source of an illustration, known as a credit line, is usually appropriate and sometimes required by the owner of the illustration. Illustrative material under copyright, whether published or unpublished, usually requires permission from the copyright owner before it can be reproduced. You cannot simply snap a photo of your favorite Picasso and use it to illustrate your history of cubism; before attempting to reproduce the painting, you must write to obtain written permission, as well as a print of the work, from the museum, or person, that owns it. Nor may you use a photograph or other portrayal of an identifiable human subject without the consent of that person or someone acting on his or her behalf. Although it is the author's responsibility, not the publisher's, to obtain permissions, the publisher should be consulted about what needs permission and the best way to obtain it. ${ }^{19}$

The section on "Lists of Illustrations" states that: "For book-length printed works, the criterion for when to include a list of illustrations is whether the illustrations are of intrinsic interest apart from the text they illustrate.... A list of illustrations may occasionally double as a list of credits if these do not appear with the illustrations themselves." 20 None of the sections mentions, defines, or explains image citations. Overall, the Chicago manual provides significant guidance to scholars who are publishing images in a book or article, but it does not consider image use by students. 
Although the Chicago manual does not have a section on citing images, there is a section on citing audiovisual materials. In fact, the Library of Congress bases its advice on how to cite photographs on Chicago's recommendations for citing audiovisual materials. This section states: "Citations of online multimedia must thoroughly identify the material cited by incorporating the elements discussed and exemplified throughout this section; it is never enough simply to cite an electronic file name or URL, though this information should be included as well." ${ }^{21}$ This exemplifies a similar approach to that found in the eighth edition of the MLA Handbook. The reader is expected to possess foundational knowledge of citing that can be applied to any type of media, including images. Neither guide discusses the purpose of image citing, the difference between captions and citations, or the elements (such as creator, title/description, medium, date, and source) that are typically included in an image caption or citation. (The Chicago manual does recommend that dimensions of works of art be given, but "only if relevant to the text, unless the rights holder requests that it be included."22)

In addition, neither guide includes a good example of an image citation. The single image citation in the MLA Handbook has a couple of problems with it. The main problem is that the image cannot be found with the citation. URLs "tend to become rapidly obsolete, ${ }^{\prime 23}$ and this one is no exception. The citation refers to an image in an online exhibition of 987 photographs, and the URL leads to the landing page of the exhibition, not a specific web page containing this image. The date of original publication is not included in the citation, but it should have been, since it "provide[s] the reader with insight into the work's creation or relation to other works"; $; 4$ in this case, it would have facilitated locating the image within the online exhibition (the exhibition can be browsed by date but not title). Searching the web does not produce the image because the web page containing the image is not indexed.

Harris, Charles “Teenie." Woman in Paisley Shirt behind Counter in Record Store. Teenie Harris Archive, Carnegie Museum of Art, Pittsburgh, teenie.cmoa.org/ interactive/index.html\#date08. ${ }^{25}$

It turns out that there is another version of this image in a digital archive (see figure 1). That version includes more descriptive data, including the name of the woman in the picture, the name of the record store, the location where the photograph was taken, the medium of the photograph, and so forth. Furthermore, the archival version is indexed and can be found with a web search. It would be preferable to cite the image in the digital archive rather than the one in the online exhibition. Another minor problem is that the photographer's name contains a pseudonym that should be in parentheses, not quotation marks, according to the guidelines provided in the MLA Handbook.

Harris, Charles (Teenie). Ellen Jane Metz in paisley shirt behind counter in Tom's record store, Homewood. c. 1967-1968. Photograph. Teenie Harris Archive, Carnegie Museum of Art, Pittsburgh. Accession number 2001.35.8516. http://teenie.cmoa.org/CollectionSearch.aspx?itemIRN=16459\&retUrl=srch $\% 3$ drecord $\% 2$ bstore $\% 26$ searchFilters $\% 3 d \% 23 \% 23 \% 23$ business $\% 3 b \% 23 \% 23$ $\% 23$ civic+life $\% 3 b \% 23 \% 23 \% 23$ entertainment+and+nightlife $\% 3 b \% 23 \% 23 \% 23$ occupations $\% 3 \mathrm{~b} \% 23 \% 23 \% 23 \mathrm{Pittsburgh}+$ views $\% 3 \mathrm{~b} \% 23 \% 23 \% 23$ politics+and +government $\% 3 \mathrm{~b} \% 23 \% 23 \% 23$ portraits $\% 3 \mathrm{~b} \% 23 \% 23 \% 23$ private+life $\% 3 \mathrm{~b} \% 23$ $\% 23 \% 23$ religion $\% 3 \mathrm{~b} \% 23 \% 23 \% 23$ sports $\% 3 \mathrm{~b}$.

The Chicago Manual of Style does not have any examples of image citations, but there are four examples of image captions. However, all of these captions are for images of 


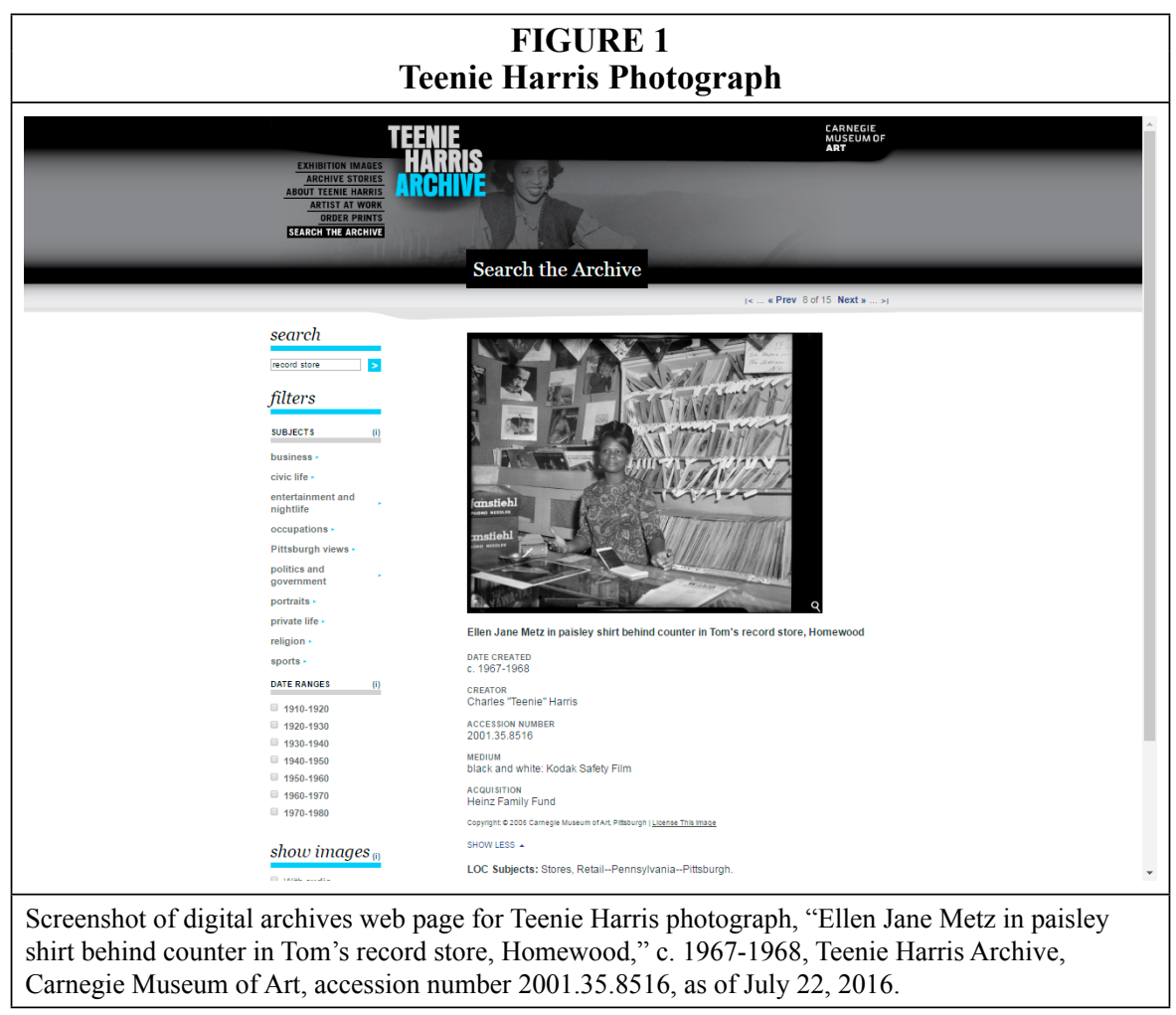

artwork, which are usually easier to caption than other types of images because little interpretation is needed to identify or describe the image. One of these examples does not provide credit, and none of them includes as much source information as one would hope to see in an image citation in a student research paper.

Frontispiece of Christian Prayers and Meditations (London: John Daye, 1569), showing Queen Elizabeth at prayer in her private chapel. Reproduced by permission of the Archbishop of Canterbury and the Trustees of the Lambeth Palace Library.

The head of Venus - a detail from Botticelli's Birth of Venus.

Francis Bedford, Stratford on Avon Church from the Avon, 1860s. Albumen print of collodion negative, $18.8 \times 28.0 \mathrm{~cm}$. Rochester, International Museum of Photography at George Eastman House.

Friedrich Overbeck and Peter Cornelius, double portrait, pencil drawing, 1812. Formerly in the Collection Lehnsen, Scarsdale, New York. ${ }^{26}$

Although there are no examples of image citations, there are several examples of citations of "online multimedia."

1. A.E. Weed, At the Foot of the Flatiron (American Mutoscope and Biograph Co., 1903), $35 \mathrm{~mm}$ film, from Library of Congress, The Life of a City: Early 
Films of New York, 1898-1906, MPEG video, 2:19, http://lcweb2.loc.gov/ammem/papr/nychome.html.

2. "HOROWITZ AT CARNEGIE HALL 2-Chopin Nocturne in Fm Op.55," YouTube video, 5:53, from a performance televised by CBS on September 22, 1968, posted by "hubanj," January 9, 2009, http://www.youtube.com/ watch? $\mathrm{v}=\mathrm{cDVBtuWkMS8}$.

Harwood, John. "The Pros and Cons of Biden." New York Times video, 2:00. August 23, 2008. http://video.on.nytimes.com/?fr_story=a425c9aca92f51bd1 9f2a621fd93b5e26650719.

\section{Pollan, Michael. "Michael Pollan Gives a Plant's-Eye View." Filmed March} 2007. TED video, 17:31. Posted February 2008. http://www.ted.com/index. php/talks/michael_pollan_gives_a_plant_s_eye_view.html. ${ }^{27}$

Rather than answering any questions, these citations of audiovisual materials raise new ones. In Chicago style, should the title of an image be provided in quotation marks or in italics? Should the medium of the picture (e.g., photograph, advertisement, etc.) be included? If relevant, should the medium of the image file (usually JPEG) be included? How should one cite an image from an image database?

The limited explanation of image citing and the insufficient number of image citations make both the MLA Handbook and Chicago Manual of Style inadequate resources for learning how to cite images properly. If a student were to read the entire $M L A$ Handbook, practice applying the framework to other types of citations, and become familiar with scholarly conventions in image captioning and citing in her field of study, then the MLA Handbook would be useful in providing a checklist of elements that should be provided in a citation. If a student were to read the Chicago manual's sections on "Captions," "Credit Lines," "Lists of Illustrations," and citing "Online Multimedia," then she would find negligible instructions on image captioning, only somewhat relevant information on attribution ("Credit Lines"), and no examples of image citations. Either style guide would be more useful if it were consulted in combination with guides that discuss image citation in an educational context and that provide a wide range of examples of image captions and citations.

\section{Other Guides}

One of the more thorough resources on image citation is the book Visual Literacy for Libraries: A Practical, Standards-Based Guide, by Nicole E. Brown, Kaila Bussert, Denise Hattwig, and Ann Medaille. The chapter on citing and crediting images covers the following: why we cite images; how to find information for a citation; and citing tips for various types of projects (research paper, poster, presentation, online space, creative work). It acknowledges many of the same deficiencies in style guides that are discussed in this paper:

"Style guides do not always provide complete or extensive discussion or examples of image citations, and citation generation and management tools are geared more for text materials." 28

The Publication Manual of the American Psychological Association (6th edition) and the MLA Handbook for Writers of Research Papers (7th edition) ${ }^{29}$ provide some guidance for image citation, but they contain a limited number of examples and 
do not account for the variety of image types and the contexts in which images may appear. In this section, we bring together image-related citation guidelines dispersed throughout the citation manuals. We suggest best practices and models for citing the types of images and sources most commonly encountered by students and faculty. ${ }^{30}$

Regrettably, the chapter missed the opportunity to establish "best practices and models." It does not provide a wide variety of examples of image captions and citations. The APA and MLA-style captions and citations are all of artwork. In addition, there are inconsistencies between the examples, making them difficult to follow. This book is a significant resource for laying down the foundations of image captioning and citing, but it could be improved with captions and citations of non-art images, as well as consistency between the examples.

On the other hand, A Manual for Writers of Research Papers, Theses, and Dissertations: Chicago Style for Students \& Researchers provides multiple examples of non-art image citations. It does not discuss image captions, but the advice on citing images is clear and concise. The manual enumerates the items that belong in a citation for a "painting, sculpture or photograph" or for a work of "graphic art," whether using NotesBibliography ${ }^{31}$ or Author-Date style: ${ }^{32}$ artist, title, date of creation, and name of housing institution; and medium, access date and $U R L$, if applicable. It further recommends that image citations be used only in notes and not in the bibliography or list of references. An example of an image citation from a book is given (here in Notes-Bibliography style):

7. Georgia O'Keeffe, The Cliff Chimneys, 1938, in Barbara Buhler Lynes, Lesley Poling-Kempes, and Frederick W. Turner, Georgia O'Keeffe and New Mexico: A Sense of Place (Princeton, NJ: Princeton University Press, 2004), 25.33

There are examples of citations of graphic sources:

12. Toyota, "We See beyond Cars" (advertisement), Architectural Digest, January $2010,57$.

15. "Republic of Letters: 1700-1750" (interactive map), Mapping the Republic of Letters, accessed February 28, 2012, https://republicofletters.standard. edu/.

18. "Divide by Zero" (Internet meme), Yo Dawg Pics, accessed December 2, 2012, http://yodawgpics.com/yo-dawg-pictures/divide-by-zero. ${ }^{34}$

The simplicity of A Manual for Writers of Research Papers and the variety and quality of the examples provided make it easy for students to use.

Another approach to teaching image citation is with a video tutorial. Elsa Loftis's "Information Literacy" tutorial on the online learning platform Lynda.com covers various topics, including "Citation for Visual Resources and Media." This video discusses the purpose of citing images, differentiates between captions and citations, and provides examples of image captions. The tutorial states that: "A caption is the text accompanying an image inserted into your paper. A citation is the reference included in your work cited page or bibliography." Further,

Both citations and captions include the artist's name, the title of the work, the date, if available, and the owner of the item.... The caption notes the dimensions and 
the medium. The citation does not. The citation includes more detailed information regarding the source of the image, and in the case of internet resources, also documents the date the image was retrieved online. ${ }^{35}$

Four examples of captions are shown, but the citations that are discussed in the tutorial are missing from the slides. Three of the captions are for artworks, and the fourth is of a digital photograph by Loftis herself. The captions are inconsistent in format and punctuation, making them difficult for students to use as examples. This tutorial would be more helpful to students if it had more examples of captions and citations of non-art images, if the examples were consistent with each other, and if there were more discussion on the difference between captions and citations.

Many Libguides, librarian-authored web resources, have been developed to help students cite images properly. There are 1,131 LibGuides ${ }^{36}$ that deal with "citing images." Libguides can be targeted to an assignment, a class, a program, or a school. They are an ideal space for displaying numerous examples of image captions and citations, of various types of images, used in multiple contexts. However, it is difficult for librarians to interpret, distill, and synthesize the disparate information found in the guides discussed in this paper. As we have seen, the MLA Handbook and Chicago Manual of Style are incomplete when it comes to the topic of image citation. Though more comprehensive, Visual Literacy for Libraries is concerned with MLA and APA styles, A Manual for Writers of Research Papers with Chicago style, and the Lynda.com tutorial with $M L A$ style, and it is not known to what extent the guidance provided in the context of one documentation style applies to other documentation styles. There are contradictions. For example, the "Information Literacy" tutorial ( $M L A$ style) states that a caption and a citation are both necessary, but A Manual for Writers of Research Papers (Chicago style) states that citations should be provided only in notes. This illustrates the need for style guides to be standard-bearers on the topic of image citation.

\title{
Image Resources
}

Image resources including the Library of Congress, AP Images, EBSCO, Artstor, and ProQuest's Vogue Archive provide varying degrees of documentation for students who are using images from their collections. The Library of Congress's web guide for teachers on "Using Primary Sources" shows students how to cite primary sources such as books, articles and essays, cartoons and illustrations, films, government publications, manuscripts, maps and charts, newspapers, oral history interviews, photographs, and sound recordings, obtained from the Library of Congress collections, using Chicago, $M L A$, and APA styles. Each type of source has the following: a checklist of items that should be included in a citation, a form of a citation, and an example of a citation. The guide on citing images in MLA style on the Library of Congress is consistent and easy to follow, but it remains to be seen if and how the guidance will be updated to match the eighth edition of the MLA Handbook, which, for example, no longer requires a medium of publication. ${ }^{37}$

\section{MLA Citation Format:}

(MLA Handbook, 7th ed., sections 5.7.6 and 5.6.2d)

\author{
Structure \\ 1. Artist last name, artist first name \\ 2. Title (italicized) \\ 3. Date of composition \\ 4. Format (photograph)
}


5. Institution that houses the work, city where the piece is located

6. Title of the database or website (italicized)

7. Medium (web)

8. Date of access

9. URL (in angle brackets) - optional

Last name, First name. Title. Date of composition. Photograph. Institution, City. Title of the website. Web. Day Month Year of access. <opt. URL>.

Example:

O'Sullivan, Timothy H. Incidents of the War. A Harvest of Death. c1865. Photograph. Lib. of Cong., Washington D.C. Lib. of Cong. Web. 27 Jan. 2016. <http://www.loc.gov/pictures/item/cwp2003001110/PP/>. ${ }^{38}$

The Library of Congress instructions on citing a photograph in Chicago style are based on the sections in the fifteenth edition of the Chicago Manual of Style on names and terms of "paintings, statues, and such" and on citing online multimedia. ${ }^{39}$

\section{Chicago Citation Format:}

(Chicago Manual of Style, 15th ed., sections 17.270, 8.206)

\section{Structure:}

1. Photographer's last name, first name, middle initial (if given). [Include role after name, i.e. photographer.]

2. "Photo Title." [Include brackets if given in bibliographic record.]

3. Format (photograph).

4. Publisher city: publishing company, copyright date (include c [circa] if given; if no date, use n.d.).

5. Source (From Library of Congress in normal font), Collection name (in italics). If no collection name, name of division where item is housed with no punctuation.

6. Medium.

7. URL (use bibliographic record URL or shorter digital ID if available at bottom of bibliographic record).

8. Accessed date (in parentheses).

Last name, First name Middle initial. Title of Work. Format. City: Publishing Company, copyright date. Source, Collection. Medium, http://...(accessed date).

\section{Example:}

O'Sullivan, Timothy, photographer. "[Incidents of the war. A Harvest of Death, Gettysburg, July 1863.]" Photograph. Washington, D.C.: Philip \& Solomons, c1865. From Library of Congress: Selected Civil War Photographs, 1861-1865. http://www.loc.gov/pictures/item/cwp2003001110/PP (accessed January 9, 2006). ${ }^{40}$

Though the Library of Congress's guidance on Chicago style does much to clarify how to cite images, there are a few confusing points. First, it recommends that square brackets are used for the title of the photograph, but the form of citation has the title 
in italics. It is not clear where the recommendation for square brackets originates: the Chicago manual (section 17.270 of the 15 th edition and section 14.280 of the 16 th edition) does not recommend the use of square brackets for titles. To add to the confusion, writers customarily use square brackets to denote text that is ancillary. Next, the date in the citation should not be restricted to "copyright date." The creation date can be just as informative and might be offered in addition to the copyright date. Third, "medium" appears in the structure and form of citation, but it is not included in the example, so it is not clear what is meant by "medium." Consulting the Chicago guide (Section 17.270 of the 15th edition) indicates that "medium" refers to the type of multimedia. (In this case, the "medium" would be a JPEG or TIFF.) Finally, there are minor inconsistencies in punctuation and structure between the form and the example.

This war photograph can be used to illustrate the subjective nature of descriptive image captioning. If this image were used in a paper on photography, the caption would probably include the photographic medium ("photographic print," "glass negative," "digital file from b\&w film copy neg.," or "digital file from intermediary roll copy film") ${ }^{41}$ If this image were used in a paper on the Battle of Gettysburg, the caption might refer to the exact point of the battle that is being depicted.

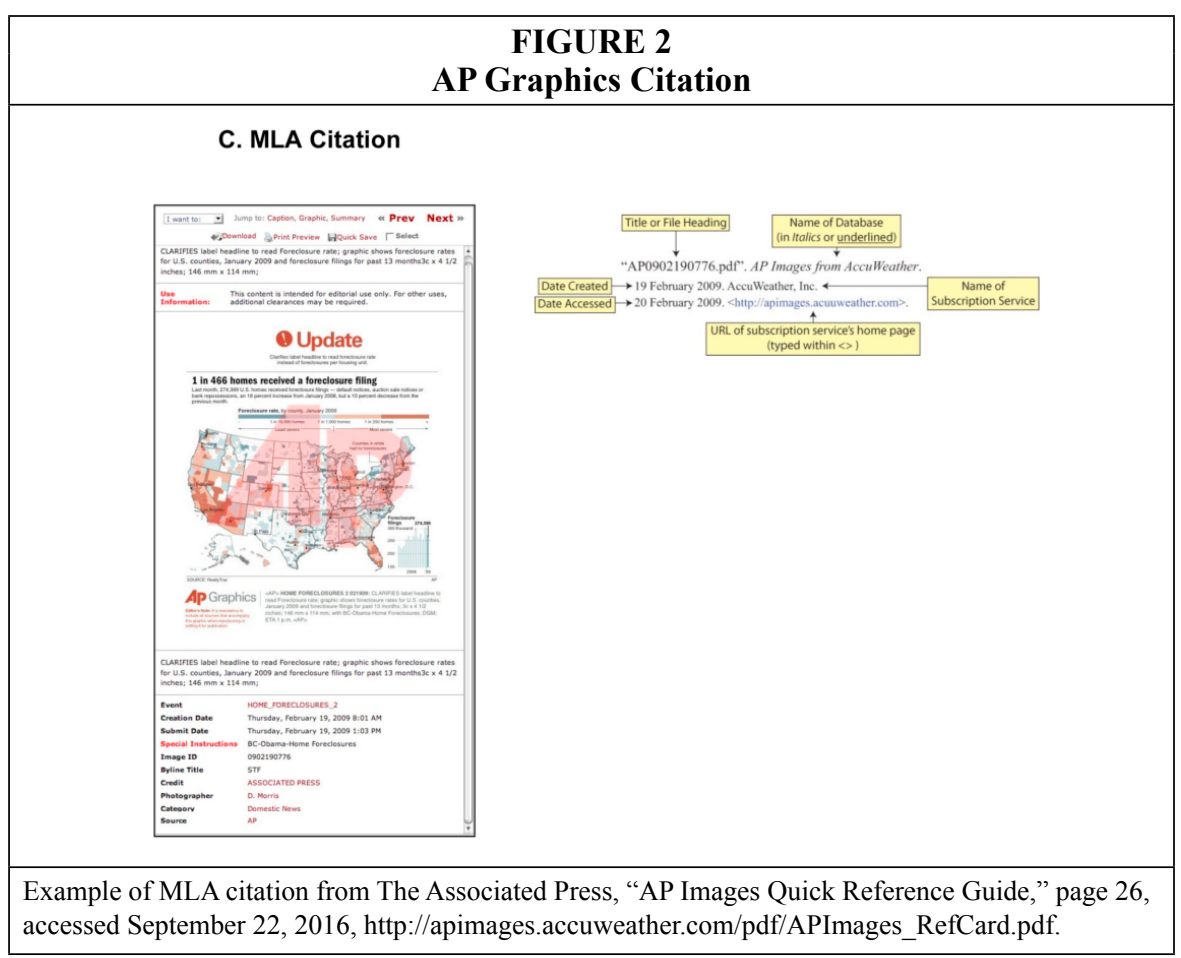

AP Images, a database of journalistic media provided by the Associated Press, is geared toward media organizations that license content, but it is also available to libraries and academic institutions. It allows downloading of low-resolution images with a "download" tool and a "quick save" tool. The guidance provided to students on citing images is provided on a separate website, AP Images by AccuWeather ${ }^{\mathrm{TM} 42}$ in the "AP Images Quick Reference Guide." ${ }^{43}$ A chart shows how to cite a graphic using $M L A$ style (see figure 2). It recommends that students include the title or file heading, 
name of database, date created, name of subscription service, date accessed, and URL of subscription service's homepage. This citation may be sufficient for citing a graphic, but it is not sufficient for citing a photograph. The photographer's name should be stated, and the "Image ID" should be included, since multiple images in AP Images can share the same title.

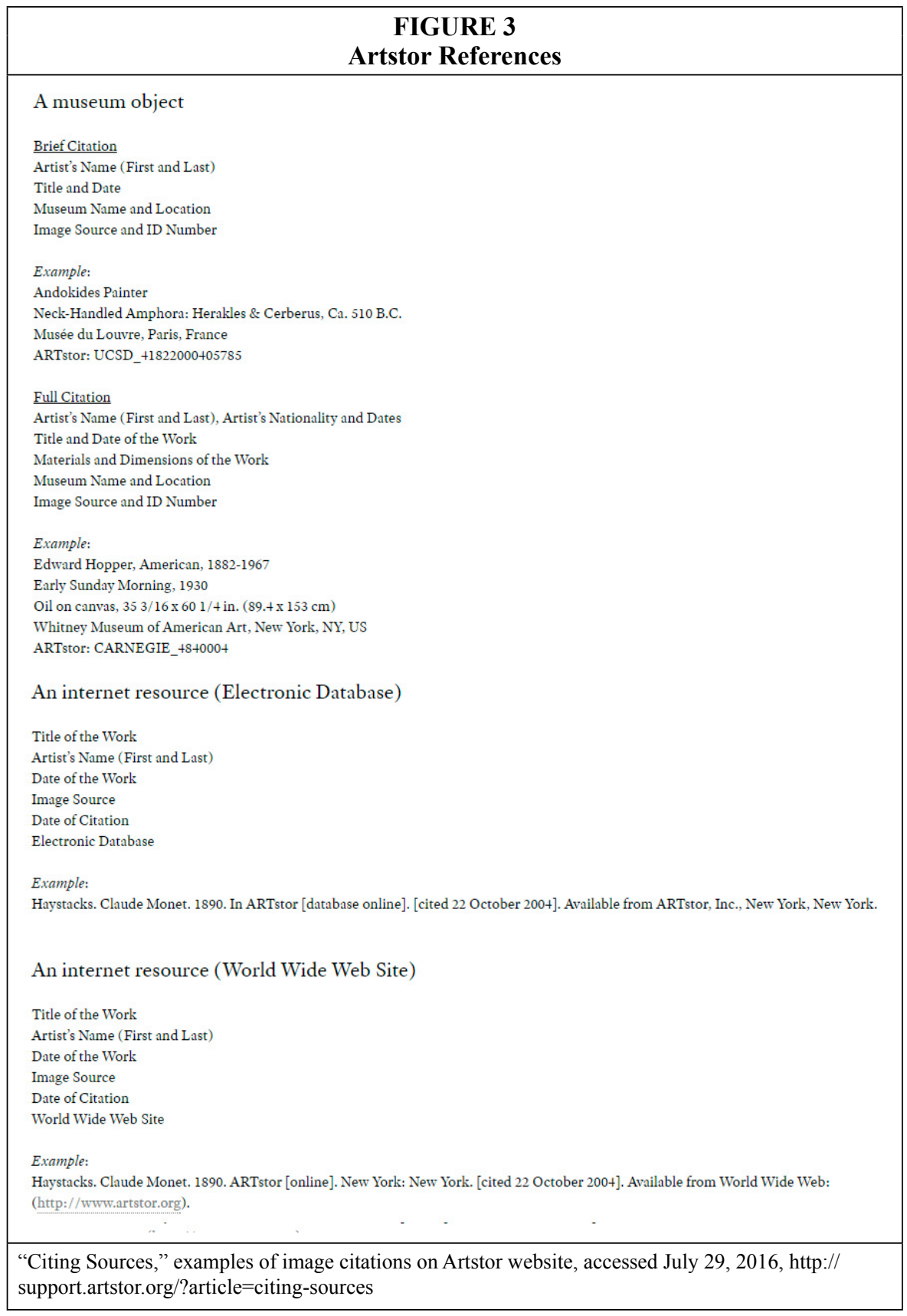


Another image database, Artstor, is a source of high-quality images of art, architecture, design, archaeology, and other subjects, from museums and other institutions from around the world, which can be used for educational and research purposes. The page on "Citing Sources" contains four examples (see figure 3). There is no mention of documentation style. Also on the page is a reference to the International Federation of Library Associations and Institutions (IFLA) website at www.ifla.org/I/training/ citation/citing.htm, ${ }^{44}$ but this IFLA webpage has not been updated since 2005. Based on the way they are formatted, Artstor's first two examples, of a "brief citation" and a "full citation," bear closer resemblance to captions than to citations. They include the elements that one would typically expect to see in a caption, including name, title, date, museum name and location, image source, and ID number for the brief version, plus artist's nationality and dates, materials, and dimensions for the full version. When attempting to locate the images in Artstor, the first example, of a Greek vase at the Louvre Museum, could not be found, although there is another image in Artstor that seems to refer to the same object but under a different title ("Amphora with Herakles and Cerberus, in the Presence of Athena (side A)"). (Note: At the time of printing, the image is again available in Artstor under the title in the caption, "Neck-Handled Amphora: Herakles \& Cerberus," but the ID number no longer appears to be associated with the image.) The second example, of an Edward Hopper painting, was easily located. This first example illustrates the possible impermanence of images obtained from image databases.

The third and fourth examples, of an "electronic resource (electronic database)" and "electronic resource (World Wide Web site)," appear to be of citations. They have the same elements as the first two examples, but museum name and location and ID number have been removed while date accessed and URL have been added. However, with the removal of these two elements, the citations do not contain enough information to find the image: a full title, museum name and location, and/or identifying number, are needed to identify the pertinent iteration of Monet's dozen or more Haystacks paintings. In summary, as many elements as possible out of the ones in Artstor's "full citation" should be included in a caption or citation to increase the likelihood of the image being found. Artstor also has a Libguide, the "Instructor's Guide to Artstor," that states that "Citing images can be tricky." 45 The guide refers students to "your university's librarians" and to the Library of Congress guide discussed in this paper.

The aggregator EBSCO provides access to images within the database EBSCO Image Collection, its reference sources, and its full-text, PDF-format periodical articles. In EBSCO's help documentation, there is a guide on "How to Cite Images:"

When referencing images that come from articles, it is perfectly acceptable to cite the parent article.

If you want to specifically cite the image, use the article citation and make the following changes:

1. Check the article content for additional source information, such as a photographer or illustrator.

If an alternate name is available, use that in place of the article's author(s).

2. If the image has a title or caption, use that in place of the article title.

3. After the article or image title and before the journal title, insert the image type. Image types are: Chart, Diagram, Graph, Illustration, Map, or Photograph.

4. Replace the page range of the article with the page number for the image. ${ }^{46}$ There are also examples of citations in six styles, including Chicago and MLA styles. 


\section{Chicago: Humanities Style \\ Article:}

Talbot, David. "Saving Holland." Technology Review 110, no. 4 (July 2007): 50-56. Academic Search Premier, EBSCOhost (accessed December 14, 2007).

\section{Image:}

Vermeer, Dura. "High and dry concept." Photograph. Technology Review 110, no. 4 (July 2007): 56. Academic Search Premier, EBSCOhost (accessed December 14, 2007).

\section{MLA Style}

\section{Article:}

Maynard, W. Barksdale. "Thoreau's House at Walden." Art Bulletin 81.2 (1999):

303. Academic Search Premier. EBSCO. Web. 19 Nov. 2002.

\section{Image:}

“Clown Fish." Getty Images. Points of View. EBSCO. Web. 30 Jan. 2007.47

The Chicago-style example clearly shows how to cite an image sourced from a periodical article from EBSCO. This example demonstrates a couple of advantages of using images from published books or periodicals, as opposed to websites or databases. First, they are often easier to cite because the bibliographic data for the citation is readily identified. Second, they often have more permanence and are easier to locate. In contrast to the Chicago-style example, the $M L A$-style image citation is not clear. Although the image citation follows the rules that have been established, it appears incomplete. It is unclear whether Points of View refers to a journal, a collection, or a database. Since the image citation does not correspond with the article citation, the image cannot be found by locating the Art Bulletin article. Moreover, the image originated from Getty Images, an outside image database with its own conventions for titling and identification. These factors make this clown fish harder to find than Nemo. In sum, the guidance on image citation provided by EBSCO is easy to follow, but the problematic $M L A$-style image citation detracts a bit from its usefulness.

ProQuest's Vogue Archive does not provide any guidance at all on citing images. When the author of this study asked the copyright holder, Condé Nast, whether there is a standard form of attribution that the company would like students to use, the company stated that the request would be reviewed and another response would be given. However, no further communications were received.

Next, this study analyzes EasyBib, a free, online citation generator. Many students use tools such as EasyBib, Endnote, Refworks, Zotero, and Cite This for Me when creating citations for their papers. EasyBib (www.easybib.com) allows users to input bibliographic information and receive formatted citations in MLA, APA, or Chicago style for fifty-nine types of resources. (The MLA-style tool is free; the others require a paid account.) The six most popular citation types are: books, digital images, films/online videos, journal articles, online databases, and websites. The fact that digital images are one of the top six resources attests to the popularity of digital image use. EasyBib can also create citations for several other visual formats, including advertisements, cartoons/comics, maps/ charts, paintings/artworks, and photographs. The author of this study selected an image from the Flickr Creative Commons to use in Easybib. The photograph depicts a man at what appears to be a public library event. He wears a name tag that reads "Kalamazoo Public Library, Jermaine Jackson, Library Assistant" on a Kalamazoo Public Library orange t-shirt. He is laughing or smiling and holds a hot dog on a plate. 
Kalamazoo Public Library. 0917 13_5457_edited-1. Events at Eastwood Branch Library. www.kpl.gov. Digital image. Flickr. Kalamazoo Public Library, 13 Sept. 2013. Web. 28 July 2016. <https://www.flickr.com/photos/kalamazoopubliclibrary/9971694663/>.

Although the citation that is provided by EasyBib can be used to locate the image in Flickr, it would not make for an interesting or descriptive caption. Like the Library of Congress example, this example also sheds light on the differences between captioning and citing. The caption for this image would most likely refer to Jermaine Jackson or to the event that is being held at the Kalamazoo Public Library. This information is not included in the citation. As previously discussed, when both a caption and citation are included, the main purpose of the caption is to connect the image with the paper and to provide credit, while the main purpose of the citation is to allow the reader to locate the image.

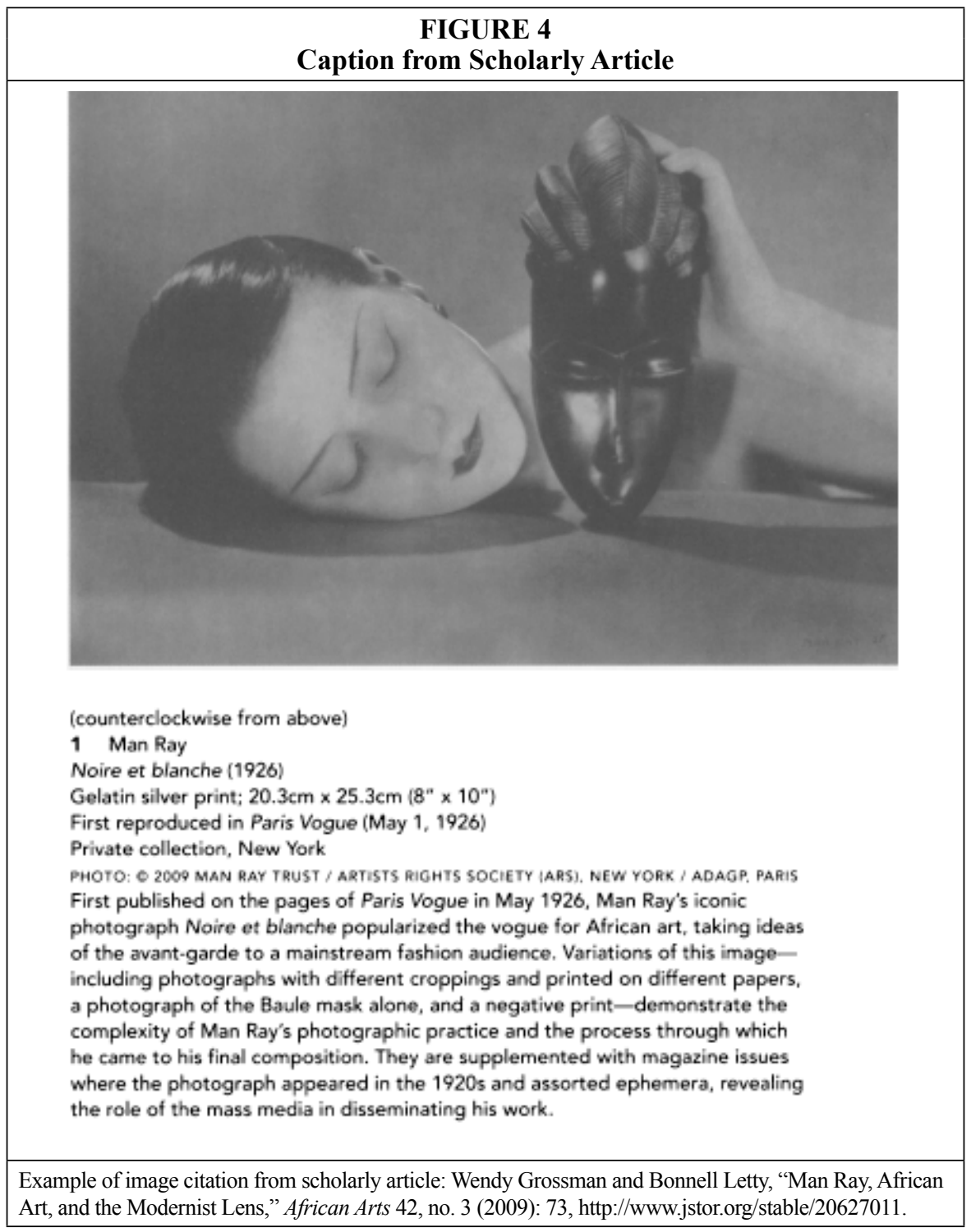




\section{Captions from Vogue}

The final part of this analysis is a brief overview of captions that have been used to describe covers, page views, and images from various editions of Vogue magazine (American, British, French, German, and Russian). All of the articles employed image captions, but no image citations. The captions varied considerably, with the simplest, from a journal on literature, reading only: "Figure 1 (from Vogue)" 48 and the longest, from an art journal, for a photograph by the artist Man Ray (see figure 4$).{ }^{49}$

The remaining examples fall somewhere in between. The earliest caption, from an interior decorating periodical from 1894, reads:

\section{PARISIAN BOUDOIR, A LA STUDIO, SHOWING JAPANESQUE ARRANGE- MENT OF DRAPERIES, FROM VOGUE..$^{50}$}

Two recent captions from 2012, from a women's studies journal and from a costume history journal, read:

\section{Fig. 1. Vogue, February 1963. EUGENE VERNIER, VOGUE @ THE CONDÉ NAST PUBLICATIONS LTD. ${ }^{51}$}

figure 2 Charles Kleibacker asymmetrical bias-cut dress. Photograph by Henry Clarke/Vogue (USA), December 1965, p. 190. (C) Condé Nast Publications Inc. ${ }^{52}$

Copyright statements are more common in recent captions, but not all of the more recent captions have them. The earliest article to include a copyright statement dates from 2004 and can be found in a journal about American periodicals.

Figure 3. Salvador Dali, cover of Vogue, June 1, 1939. Courtesy of Vogue (C) Conde Nast Publications. ${ }^{53}$

The varying captions in this study exemplify the divergent captioning practices across different scholars and different journals. Prevalent elements found in recent captions include: an artist or creator's name, the date of the issue of Vogue, and a credit line for Condé Nast. The more inconsistently used elements include a title or description, and page number. These examples show how scholarly practices in image captioning are not standardized; therefore, students will need at least a fair amount of guidance in the classroom when captioning images for research papers.

\section{Recommendations}

In the course of performing this study of existing style guides, resources on image citing, and captioning practices, the author developed some recommendations. Some of these ideas may be useful if included in future style guides:

- The quality of the citation depends on the image source. Images obtained from published works such as books and articles are easier to cite, since documentation standards for these sources are more long-standing. (The maxim "Garbage in, garbage out" applies.) Digital images should be traced back to their "original" or most "permanent" source, and that version should be cited.

- A caption is primarily used to identify or describe an image and to give credit; a citation is primarily used to provide the source of the image so that it can be retrieved. At a minimum, the caption should include a title or description, as well as a credit line. The citation requires a varying amount of information, depending on the type of image being cited and its source, but it will usually 
include at least a creator, title or description, and source. For images from websites and databases, identifying numbers are incredibly useful.

- Both a caption and a citation are not always necessary. A student research paper should include both a caption and citation, or a combination caption/citation. In websites, e-portfolios, and other digital platforms, it may be sufficient to provide only a caption and a link, embedded into the caption and/or the image, which refers to the "original" image (following the conventions for online posting). For a presentation, it may be appropriate to provide only a short credit statement as the caption, plus a list of image citations.

- In published works such as books and journal articles, captions are jointly determined by the author, the field of study, the copyright holder, the editor, and the publisher. In the classroom, caption standards are determined by instructors.

- The quality of a caption depends on a writer's subject knowledge. Describing the image, interpreting the image, or relating the image to the text is necessary to provide an informative caption. Research (on related images, copyright, or collection information) may be needed to fittingly caption an image. ${ }^{54}$

- A citation should include as much information as is necessary to locate the image. Creation or publication dates, page numbers, identification numbers, collections, repositories, and URLs greatly assist in this regard.

- Plenty of carefully prepared examples of both captions and citations should be provided. Examples should include non-art photographs and graphic works such as periodical covers or pages, advertisements, posters, illustrations, maps, manuscripts, letters, and ephemera. Examples of captions/citations for images being posted online should be included. A few examples of image citations should be added to the Chicago Manual of Style's online "Quick Guide." 55

- $\quad$ Standardized, prescribed formatting and punctuation, provided in examples of image citations, serve multiple purposes. For the title or description of the image, formatting can indicate whether or not the title was provided in the source. Formatting can also clarify whether a source is a periodical, collection, website, or database. ${ }^{56}$ Stated conventions for formatting and punctuation would allow students to focus on important aspects of scholarship, rather than asking themselves what would work best for each and every citation.

\section{Conclusion}

This paper has demonstrated how two style guides that are widely used by college and graduate students, the MLA Handbook and Chicago Manual of Style, do not provide specialized guidance on image captioning and citing, which is necessary for students to "cite visual materials using an appropriate documentation style," a learning outcome of the ACRL Visual Literacy Standards. The books Visual Literacy for Libraries and A Manual for Writers of Research Papers, and the Lynda.com video tutorial on "Information Literacy," fill gaps in image captioning and citing guidance, but they depend on the guidance provided by style guides, and they do not substitute for the style guides. The guidance on image citation from image sources such as the Library of Congress digital collections, AP Images, Artstor, EBSCO, and ProQuest Vogue Archive, is nonexistent, incomplete, or inconsistent. Citation generators such as Easybib disregard image captions, and, conversely, scholarly journal articles typically omit image citations.

As visual literacy becomes more important, it is necessary for style guides to provide more comprehensive information about image captioning and citing. They should: explain to students why we cite; distinguish between captions and citations; discuss the elements that are typically included in each; and show various examples. The ideas and recommendations provided in this study can act as a springboard or outline for future guidance. 
Until style guides are updated, librarians can provide guidance on image captioning and citing to students (and faculty) in Libguides and in other forms of instruction. Communities of practice might provide guidelines on captioning and citing images, just as they have for fair use. Image sources might offer guidelines on how to caption and cite, as the Library of Congress has done. (They can also provide a unique identifier for each image.) For many students, captioning and citing images might seem daunting at first, but given clear guidelines and the opportunity to practice, they should grow to appreciate the art and science of image captioning and citation.

\section{Notes}

1. American Association of School Librarians, Standards for the 21st-Century Learner (Chicago, Ill.: American Library Association, 2007), available online at www.ala.org/aasl/sites/ala.org.aasl/ files/content/guidelinesandstandards/learningstandards/AASL_LearningStandards.pdf [accessed 25 August 2016].

2. "ACRL Visual Literacy Competency Standards for Higher Education," approved by the ACRL Board of Directors, October 2011, available online at www.ala.org/acrl/standards/visualliteracy [accessed 25 August 2016].

3. Ibid.

4. Ibid.

5. John Abdul Kargbo, “Undergraduate Students' Problems with Citing References," Reference Librarian 51 (2010): 222-36, doi:10.1080/02763871003769673.

6. Denise Hattwig, Kaila Bussert, Ann Medaille, and Joanna Burgess, "Visual Literacy Standards in Higher Education: New Opportunities for Libraries and Student Learning," portal: Libraries and the Academy 13, no. 1 (2013): 83, ProQuest Central, ProQuest [accessed 31 August 2016].

7. Benjamin R. Harris, "Image-Inclusive Instruction," College and Undergraduate Libraries 14, no. 2 (2007): 65-75.

8. Molly J. Schoen, "Teaching Visual Literacy Skills in a One-Shot Session," VRA Bulletin 41, no. 1 (Jan. 2015): 1-12, available online at http://online.vraweb.org/cgi/viewcontent. cgi? article $=1048 \&$ context $=$ vrab [accessed 31 August 2016] .

9. Debbie Abilock, "Adding Friction: How to Design Deliberate Thinking into the Research Process: How Should I Cite an Image from Google?" Library Media Connection (Mar./Apr. 2014): 36-37, Academic Search Complete, EBSCO [accessed 31 August 2016].

10. Gail Lynn Goldberg, "One Thousand Words, Plus a Few More, Is Just Right," Phi Delta Kappan 96, no. 3 (Nov. 2014): 49-53, SAGE Journals [accessed 31 August 2016].

11. Winterthur Portfolio, The University of Chicago Press Journals, e-mail message to ARLIS (Art Libraries Society of North America) listserv, June 13, 2016.

12. The Online Writing Lab (OWL) at Purdue University, "MLA Style," available online at https://owl.english.purdue.edu/owl/section/2/11/ [accessed 4 March 2017].

13. The Online Writing Lab (OWL) at Purdue University, "Chicago Manual of Style 16th edition," available online at https://owl.english.purdue.edu/owl/resource/717/01/ [accessed 4 March 2017].

14. "ACRL Visual Literacy Competency Standards for Higher Education."

15. Ibid.

16. MLA Handbook, 8th ed. (New York, N.Y.: Modern Language Association of America, 2016), xi.

17. The Chicago Manual of Style, 16th ed. (Chicago, Ill.: University of Chicago Press, 2010): Table of Contents, available online at www.chicagomanualofstyle.org/16/ch03/ch03_toc.html [accessed 4 March 2017].

18. Chicago Manual of Style, Section 3.21.

19. Chicago Manual of Style, Section 3.28.

20. Chicago Manual of Style, Section 3.37.

21. Chicago Manual of Style, Section 14.280.

22. Chicago Manual of Style, Section 3.27.

23. MLA Handbook, 48.

24. MLA Handbook, 50.

25. MLA Handbook, 41.

26. Chicago Manual of Style, Section 3.22 .

27. Chicago Manual of Style, Section 14.280.

28. Nicole E. Brown et al., Visual Literacy for Libraries: A Practical, Standards-Based Guide (Chicago, Ill.: ALA Editions, 2016), 129.

29. Visual Literacy for Libraries uses the seventh edition of the MLA Handbook, but the seventh and eighth editions do not differ substantially in terms of their treatment of image citation. 
30. Brown, Visual Literacy for Libraries, 132.

31. Kate L. Turabian, A Manual for Writers of Research Papers, Theses, and Dissertations: Chicago Style for Students \& Researchers, 8th ed., rev. Wayne C. Booth, Gregory G. Colomb, Joseph M. Williams, and the University of Chicago Press Editorial Staff (Chicago, Ill.: University of Chicago Press, 2013), 200.

32. Turabian, A Manual for Writers, 263.

33. Ibid.

34. Ibid, 264.

35. Elsa Loftis, "Citation for Visual Images and Media," in Information Literacy, Lynda.com video, 2:20, available online at https://www.lynda.com/Higher-Education-tutorials/Citationvisual-images-media/368046/420135-4.html [accessed 22 September 2016].

36. The phrase "citing images" results in 1,131 guides from the Springshare Community website as of August 16, 2016: See: http://community.libguides.com/?action=1\&keyword=\%22citing\%20 images $\% 22$.

37. See The Online Writing Lab (OWL) at Purdue University, "MLA Eighth Edition: What's New and Different," available online at https://owl.english.purdue.edu/owl/resource/747/22/ [accessed 4 March 2017], for a discussion of the differences between the seventh and eighth editions of the MLA Handbook.

38. Library of Congress, "MLA [Using Primary Sources for Teachers]," available online at http://www.loc.gov/teachers/usingprimarysources/mla.html [accessed 13 September 2016].

39. The fifteenth and sixteenth editions of the Chicago Manual of Style do not differ substantially in their treatment of these subjects.

40. Library of Congress, "Chicago [Using Primary Sources for Teachers]," available online at http://www.loc.gov/teachers/usingprimarysources/chicago.html [accessed 13 September 2016].

41. Library of Congress, "Incidents of the War. A Harvest of Death, Gettysburg, July, 1863," available online at www.loc.gov/pictures/item/cwp2003001110/PP [accessed 13 September 2016].

42. The Associated Press, "AP Images from ACCUWEATHER," copyright 2016, available online at http://apimages.accuweather.com/ap_userguide.asp [accessed 22 September 2016].

43. The Associated Press, "AP Images Quick Reference Guide," available online at http:// apimages.accuweather.com/pdf/APImages_RefCard.pdf [accessed 22 September 2016].

44. Artstor, "Citing Sources," available online at http://support.artstor.org/?article=citingsources [accessed 29 July 2016].

45. Artstor, "Citing images," from "Instructor's Guide to Arstor," available online at https:// artstor.libguides.com/c.php?g=505857\& $\mathrm{p}=4880894 \#$-lg-box-15322934 [accessed 3 October 2016].

46. EBSCO, "How to Cite Images," available online at http://support.ebsco.com/help/index. php?help_id=1590 [accessed 5 October 2016].

47. Ibid.

48. Charles Harmon, "'Abysses of Solitude': Acting Naturally in 'Vogue' and 'The Awakening,'” College Literature 25, no. 3 (1998): 57, available online at www.jstor.org/stable/25112403 [accessed 13 April 2015].

49. Wendy Grossman and Bonnell Letty, "Man Ray, African Art, and the Modernist Lens," African Arts 42, no. 3 (2009): 73, available online at www.jstor.org/stable/20627011 [accessed 13 April 2015].

50. Carrie May Ashton, “Decorative Draperies," Decorator and Furnisher 24, no. 1 (1894): 19.

51. Becky E. Conekin, “Eugene Vernier and 'Vogue' Models in Early 'Swinging London': Creating the Fashionable Look of the 1960s," Women's Studies Quarterly 41, no. 1/2 (2012): 89-107, available online at www.jstor.org/stable/23611773 [accessed 13 April 2015].

52. Anne Bissonnette, "Savoring the Process: Designer, Educator, and Curator Charles Kleibacker," Dress 38, no. 1 (2012): 6.

53. Hannah Crawford, "Surrealism and the Fashion Magazine," American Periodicals 14, no. 2 (2004): 221, available online at www.jstor.org/stable/20770930 [accessed 13 April 2015].

54. In two studies, students found it difficult to describe and interpret images that they did not have prior subject knowledge of. Joan E. Beaudoin, "Describing Images: A Case Study of Visual Literacy among Library and Information Science Students," College \& Research Libraries 77, no. 3 (2016): 376-92; Eva Brumberger, "Visual Literacy and the Digital Native: An Examination of the Millennial Learner," Journal of Visual Literacy 30, no. 1 (2011): 19-46.

55. Chicago Manual of Style, "Chicago-Style Citation Quick Guide" (2010), available online at www.chicagomanualofstyle.org/tools_citationguide.html [accessed 11 March 2017].

56. The author of this study recommends that for Chicago style, formal titles of images be italicized, descriptions be in quotation marks when taken from the source, and author's own descriptions be set in roman type. Furthermore, periodicals should be italicized, and collections, websites, and databases should be set in roman type. URLs and unique identifiers should be provided whenever they are available. 